\title{
Thermal cyclisation reactions of methyl 2-(pyrrol-1-yl)cinnamate and methyl 3-(1-phenylpyrrol-2-yl) propenoate
}

\author{
Hamish McNab, ${ }^{* \dagger}$ David Reed, Iain D. Tipping, and Richard G. Tyas \\ School of Chemistry, The University of Edinburgh, West Mains Road, Edinburgh EH9 3JJ, UK \\ E-mail: $\underline{H . M c N a b @ e d . a c . u k}$
}

\begin{abstract}
Flash vacuum pyrolysis (FVP) of the pyrrolylcinnamate derivative $\mathbf{3}$ gives the pyrrolo[1,2a] quinoline 10, the pyrrolo[2,1-a]isoindole $13(\mathrm{R}=\mathrm{Me})$ and the benzindoles 14 and 15, all in low yield, whose structures were determined by NMR methods. The isomeric precursor 4 cyclises efficiently under the same conditions to give the pyrrolizin-3-one $\mathbf{1 6}$.
\end{abstract}

Keywords: Flash vacuum pyrolysis, heterocyclisations, pyrroles, electrocyclisation

\section{Introduction}

In previous work we have established a versatile elimination-cyclisation sequence for the formation of fused pyrrol-2-one units (e.g. pyrrolizin-3-one 1) under flash vacuum pyrolysis (FVP) conditions (Scheme 1). ${ }^{1}$

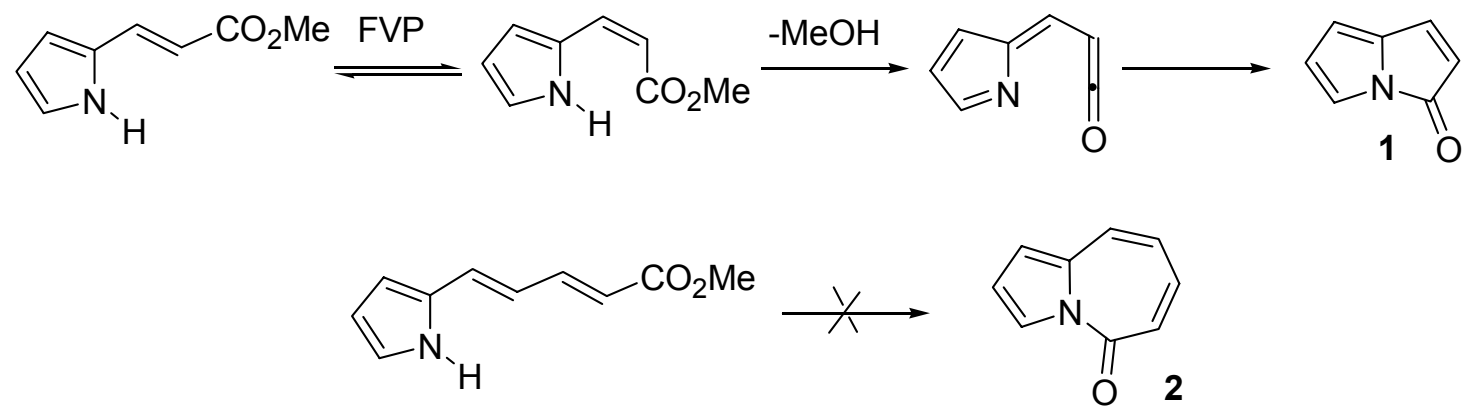

\section{Scheme 1}

Although the general strategy was shown to be applicable to the synthesis of a variety of ring systems, attempted formation of the azepinone $\mathbf{2}$ by FVP of a vinylogous precursor was not

\footnotetext{
${ }^{\dagger}$ Hamish McNab was Secretary and Treasurer of the RSC Heterocyclic Group during the period 1989-1992
} 
successful. ${ }^{1}$ This disappointing result may be due to the rotational degrees of freedom in the diene precursor at the high pyrolysis temperatures (Scheme 1). In order to probe this issue further, we reasoned that the incorporation of a fused benzene ring as part of the diene system would reduce these degrees of freedom and so might favour cyclisation to the larger ring size. For the synthesis of benzannelated pyrrolizin-3-ones, we have shown that the corresponding 1arylpyrroles are useful starting materials, since they undergo a 1,5-aryl shift under FVP conditions prior to the elimination and cyclisation sequence (Scheme 2$)^{2}$

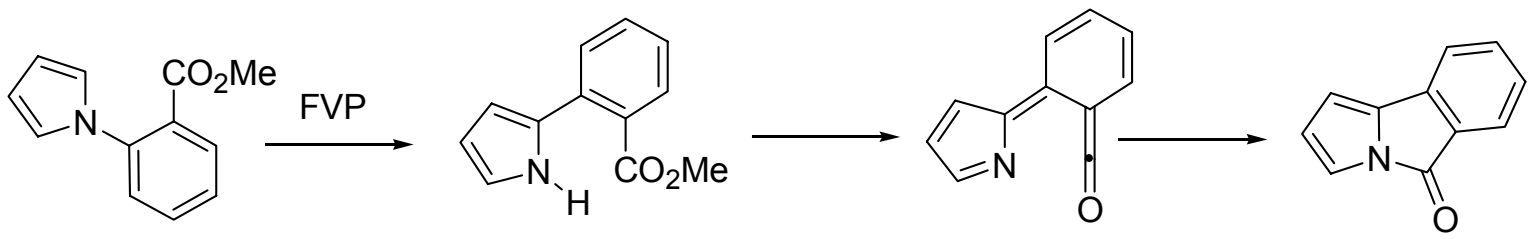

\section{Scheme 2}

The cinnamate ester $\mathbf{3}$ was therefore selected as the initial target for the work reported in this paper. In the event, this precursor did not lead to seven-membered rings but instead has resulted in the discovery of a new type of electrocyclisation-elimination process. The contrasting thermal behaviour of the isomeric precursor $\mathbf{4}$ is also reported.
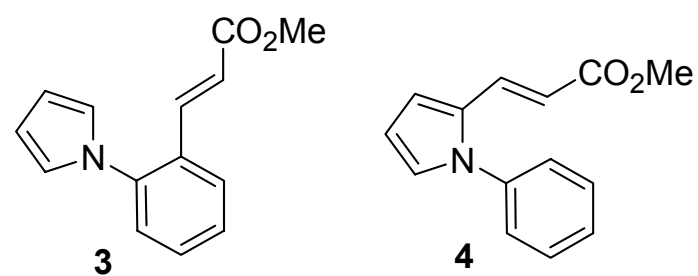

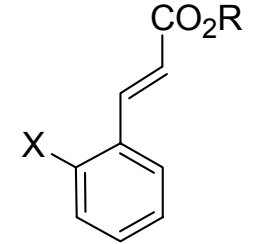

5, $\mathrm{R}=\mathrm{H}, \mathrm{X}=\mathrm{NO}_{2}$

6, $\mathrm{R}=\mathrm{Me}, \mathrm{X}=\mathrm{NO}_{2}$

7, $\mathrm{R}=\mathrm{Me}, \mathrm{X}=\mathrm{NH}_{2}$

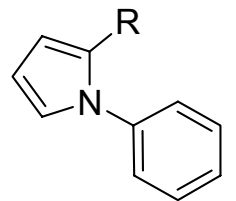

8, $\mathrm{R}=\mathrm{H}$

9, $\mathrm{R}=\mathrm{CHO}$

\section{Results and Discussion}

The precursor 3 was made from 2-nitrocinnamic acid 5 by sequential formation of the ester $\mathbf{6}$ (64\%), selective reduction to the amino compound 7 by zinc dust in the presence of ammonium chloride $^{3}(51 \%)$ and formation of the pyrrole ring by condensation with 2,5dimethoxytetrahydrofuran (54\%). The crude precursor 3 was purified by dry-flash chromatography and characterised by standard methods. Its ${ }^{1} \mathrm{H}$ NMR spectrum confirms that the $E$-configuration of the alkene unit has been maintained throughout the reaction sequence $\left({ }^{3} J 16.0\right.$ $\mathrm{Hz}$ ). A phenyl-substituted analogue of $\mathbf{3}$, prepared by a different route, has been reported. ${ }^{4}$ The 
isomeric precursor 4 was made by formylation of 1-phenylpyrrole 8 and separation of the 2carboxaldehyde isomer 9 ( $91 \%$ of the mixture), followed by Wittig reaction.

FVP of the cinnamate 3 was carried out over a range of furnace temperatures, and it was found that $850{ }^{\circ} \mathrm{C}$ was required for complete conversion to products. Four significant products were isolated in low yield by dry-flash chromatography of the pyrolysate (Scheme 3). The first product (8\%) showed a molecular ion at $\mathrm{m} / \mathrm{z} 167$ and was identified as pyrrolo[1,2-a]quinoline 10 by comparison with literature data. ${ }^{5,6}$ These data serve to exclude the isomeric pyrrolo[2,1a] isoquinoline 11, ${ }^{7}$ which might have been formed by loss of $\mathrm{CO}$ from the anticipated pyrroloazepinone product $\mathbf{1 2}$. The connectivity of $\mathbf{1 0}$ is the same as in the starting material and so it follows that a novel direct cyclisation mechanism must take place which is of lower (or at least comparable) activation energy than the initial 1,5-aryl shift of the expected cascade process.
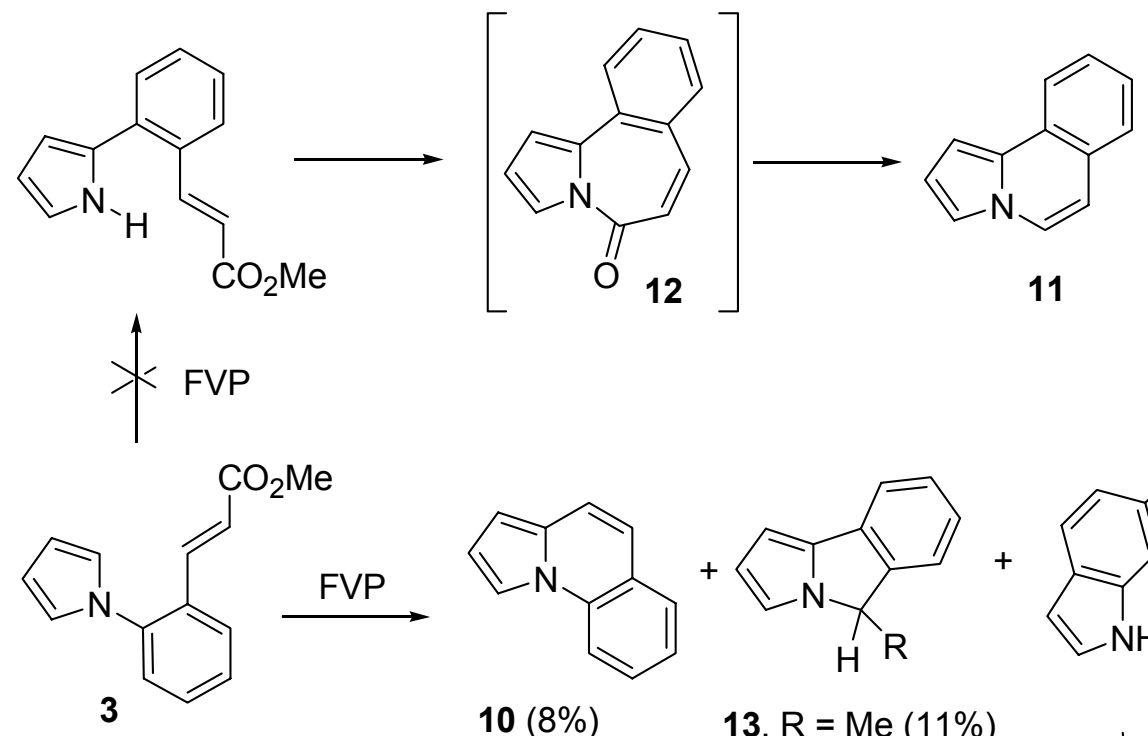

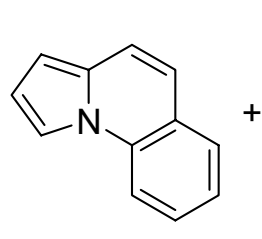

$10(8 \%)$

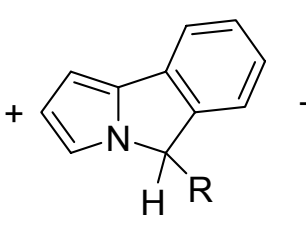

13, $R=\operatorname{Me}(11 \%)$

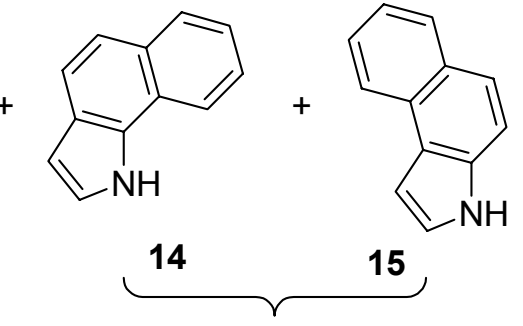

$(14 \%$ in total)

\section{Scheme 3}

The second product $(\mathrm{m} / \mathrm{z} 169)$ was obtained in low yield $(<11 \%)$ as the major component of an impure fraction. The most significant features of its ${ }^{1} \mathrm{H}$ NMR spectrum were a mutually coupled doublet $\left(\delta_{\mathrm{H}} 1.68\right)$ and quartet $\left(\delta_{\mathrm{H}} 5.08\right)$ in $3: 1$ integral ratio. The ${ }^{13} \mathrm{C}$ NMR spectrum showed one methyl group and eight $\mathrm{CH}$ resonances, one of which was in the aliphatic region $\left(\delta_{\mathrm{C}}\right.$ 56.9), apparently attached to a nitrogen atom. A NOESY spectrum indicated that the methyl group was close in space to an aromatic proton as well as the aliphatic $\mathrm{CH}$ to which it is coupled. The pyrrolo[2,1-a] isoindole structure $\mathbf{1 3}(\mathrm{R}=\mathrm{Me})$ is consistent with these data. Although this is not a known compound, the methylene protons of the parent pyrrolo[2,1- $a$ ] isoindole $13(\mathrm{R}=\mathrm{H})$ resonate at $\delta_{\mathrm{H}} 4.92,{ }^{8,9}$ very close to the value reported above for $\mathbf{1 3}(\mathrm{R}=\mathrm{Me})$, and the remainder of the spectra are very similar $\left[\mathbf{1 3}(\mathrm{R}=\mathrm{H})\right.$, aromatic protons $\delta_{\mathrm{H}} 7.1-7.3$, pyrrole-type protons $\delta_{\mathrm{H}}$ 
6.3-7.0 $;^{8,9} 13(\mathrm{R}=\mathrm{Me})$, aromatic protons $\delta_{\mathrm{H}}$ 7.2-7.5, pyrrole-type protons, $\delta_{\mathrm{H}}$ 6.3-7.0]. Although present in low yield, this product shows skeletal connectivity derived from an initial 1,5-aryl shift and must therefore be formed in preference to products of the expected eliminationcyclisation sequence (e.g. 11) shown in Scheme 3.

The final two products ( $14 \%$ in total) were closely related; although they co-eluted from the column, a pure sample of the component which was slightly more polar was obtained. Both products showed the presence of an $\mathrm{NH}$ signal in their ${ }^{1} \mathrm{H}$ NMR spectra, together with two other signals due to pyrrole-type protons and six signals in the aromatic region. The product which was not obtained in pure form, was unambiguously identified by comparison of its spectra with those reported for $1 H$-benz $[g]$ indole 14 (see Experimental section). ${ }^{10}$ In particular the ${ }^{13} \mathrm{C}$ NMR spectra are closely comparable. The remaining isomer $(\mathrm{m} / \mathrm{z} 167)$, which was obtained in a pure state, was identified as $3 H$-benz $[e]$ indole 15 by the following NMR experiments. (The reported spectra of $\mathbf{1 5}$ are not sufficiently clear to allow unambiguous identification. ${ }^{11}$ ) NOESY (and COSY) correlations between the aromatic doublets at $\delta_{\mathrm{H}} 7.57$ and 7.64 define the 1,2-fusion of the naphthalene ring and a NOESY correlation between the pyrrole-type proton at $\delta_{\mathrm{H}} 7.14$ and the aromatic doublet at $\delta_{\mathrm{H}} 8.27$ defines the mode of fusion of the heterocycle. Further NOESY correlations allow a complete assignment of the ${ }^{1} \mathrm{H}$ NMR spectrum and subsequent ${ }^{13} \mathrm{C}$ assignments were gained as a result of an HSQC experiment (Figure 1).
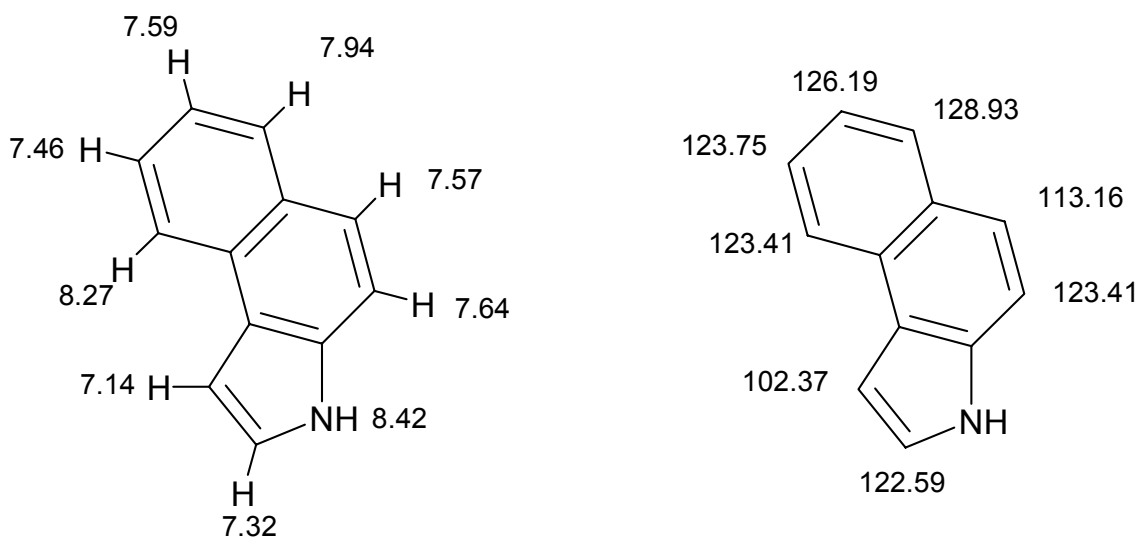

Figure 1. ${ }^{1} \mathrm{H}$ and ${ }^{13} \mathrm{C}$ NMR assignment of $\mathbf{1 5}$.

In view of the unexpected nature of the results of this pyrolysis experiment, it was of interest to study the thermal behaviour of the isomeric pyrrole 4 . In this case FVP at $850{ }^{\circ} \mathrm{C}$ gave a single main product which was identified as the pyrrolizin-3-one 16 (38\% after chromatography) by comparison of its spectra with those of an authentic sample (Scheme 4). ${ }^{1}$ In contrast to the pyrrole derivative $\mathbf{3}$, therefore, in the case of $\mathbf{4}$ a 1,5-sigmatropic shift of the phenyl group takes place (regiospecifically to the 5-position) followed by elimination of methanol to generate the ketene $\mathbf{1 7}$ and electrocyclisation to the pyrrolizinone $\mathbf{1 6}$ (Scheme 4). 
These results clearly demonstrate that the anticipated rearrangement-eliminationcyclisation cascade dominates the FVP reactions of $\mathbf{4}$, though no products are formed by this sequence in the FVP reactions of 3. Possible reasons for this are discussed below.

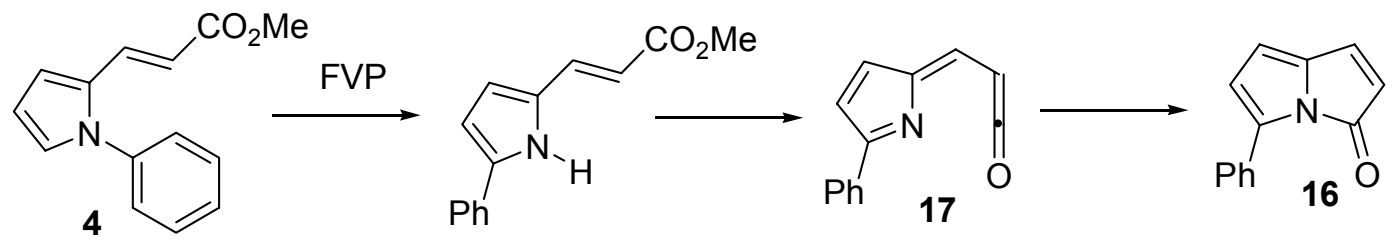

\section{Scheme 4}

In pyrolysis of $\mathbf{3}$, the product $\mathbf{1 0}$ is obtained without skeletal rearrangement but with loss of the entire ester function; such a cyclisation mechanism appears to be unprecedented. Our suggested route involves an initial 10-electron (disrotatory) electrocyclisation to provide the extended dipolar species 18 (Scheme 5). This may take place either with the $E$-cinnamate 3a or with the $Z$-isomer $\mathbf{3 b}$; $E$-Z-isomerisation of cinnamate esters is known to be essentially equilibrated at $850{ }^{\circ} \mathrm{C}$ under FVP conditions. ${ }^{12}$ Aromaticity of both the pyrrole and the benzene ring may be restored prior to the elimination step, by a 1,8-hydrogen shift from 18 to provide the 4,5-dihydro compound 19 (Scheme 5). There is good evidence that this route is followed in related cases. ${ }^{13}$

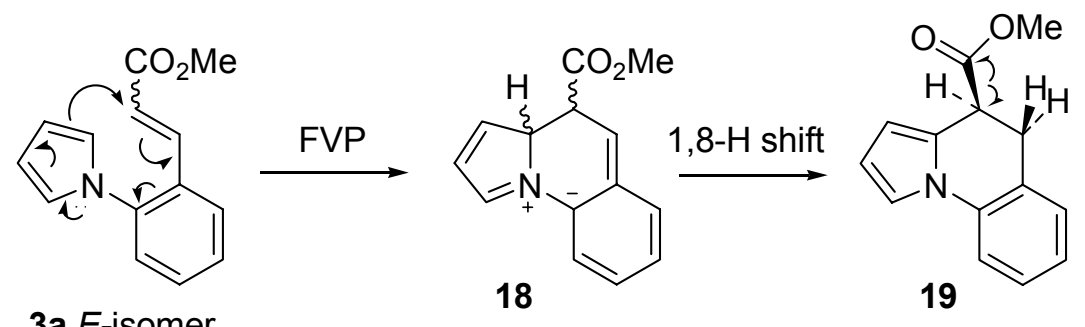

3b Z-isomer

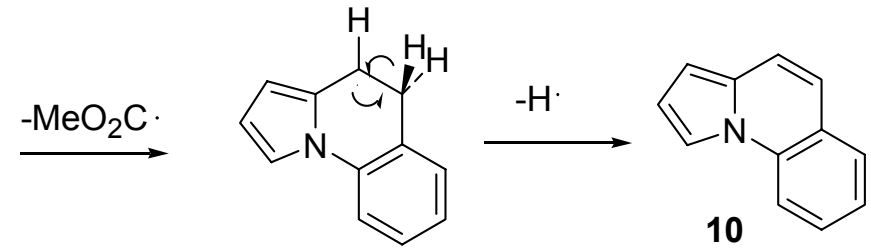

\section{Scheme 5}

The oxidative elimination step which leads from 19 to $\mathbf{1 0}$ appears to be a novel thermal behaviour of esters, though the high temperature elimination of sulfonyl groups to generate stilbene sub-units has some similarity. ${ }^{14}$ The study of model compounds, to be published elsewhere, suggest that at high temperatures the $\mathrm{CO}_{2} \mathrm{Me}$ group, when it is situated in a benzylictype position, is able to function as a radical leaving group leading (after subsequent loss of $\mathrm{H}$ ) 
to the oxidative elimination reaction observed in the pyrolysis of $\mathbf{3}$. It is also of interest that the thermal elimination of sulfinate from sulfones to give stilbene-type products, takes place by a radical mechanism. ${ }^{14}$ The most likely mechanism for oxidative elimination step in the formation of $\mathbf{1 0}$ from 3, therefore involves radical cleavage of the ester group to form a radical stabilised by the adjacent pyrrole ring, which can lose a hydrogen atom to form 10 (Scheme 5).

Though a similar electrocyclisation mechanism to that in Scheme 5 can be drawn for the FVP of 4, in this case the 1,5-aryl shift (leading to the pyrrolizinone 16) is lower in energy. Electronic effects are unlikely to account for this result; electron withdrawing groups generally migrate better in 1,5-sigmatropic shifts (though the effect may be masked for aryl migrations ${ }^{15}$ ) so, paradoxically, the 1,5-aryl shift might be expected to be relatively favoured for $\mathbf{3}$ rather than 4. Though the experimental results are clear, the reasons for the contrasting behaviour of $\mathbf{3}$ and $\mathbf{4}$ remain unknown.
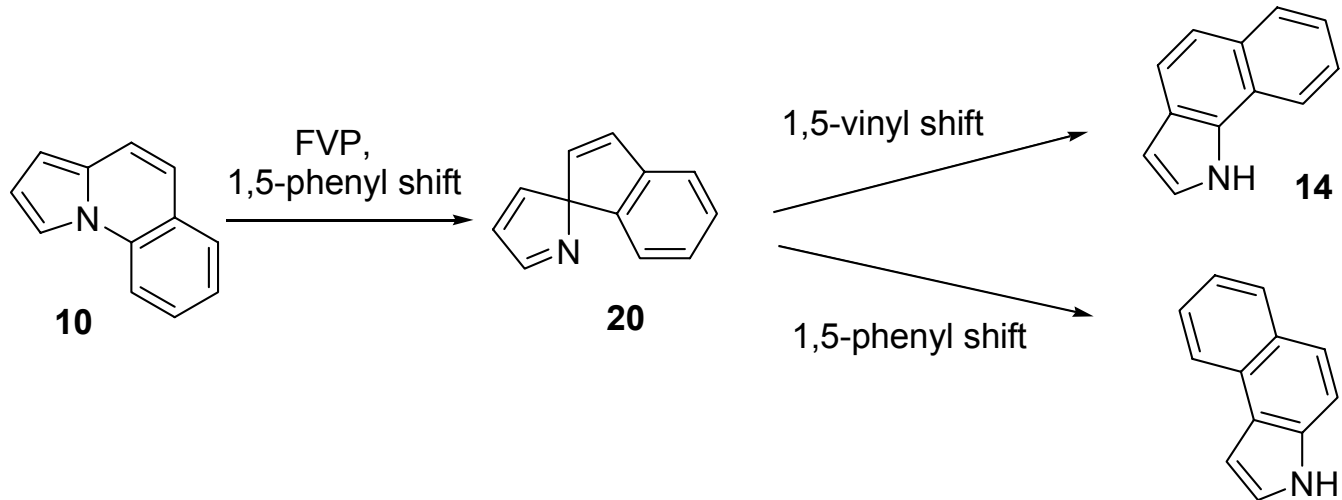

15

\section{Scheme 6}

It was thought initially that the benzindoles 14 and 15 could be derived from the pyrroloquinoline $\mathbf{1 0}$ by a sequence of 1,5-shifts via $\mathbf{2 0}$ as the key intermediate. (Scheme 6). However, control pyrolyses of 10 at $850{ }^{\circ} \mathrm{C}$ and even at $950{ }^{\circ} \mathrm{C}$ showed no trace of these potential rearrangement products and so it is likely that they are formed by a different mechanism. Thus, initial 1,5-shift(s) of the aryl group can generate the 2- and 3-arylpyrroles 21 and 22 respectively. Compounds 14 and 15 can then be formed by electrocyclisation followed by 1,5-hydrogen shift and elimination of the ester moiety in a similar fashion to the formation of $\mathbf{1 0}$ (Scheme 7 - c.f. Scheme 5). Once the 1,5-aryl shift has taken place, therefore, we believe that the novel ester elimination route is favoured over the expected ketene formation by methanol elimination. These results suggest that such an elimination step, requiring an eight or ninemembered transition state, is simply not viable, allowing the other processes to intervene. 


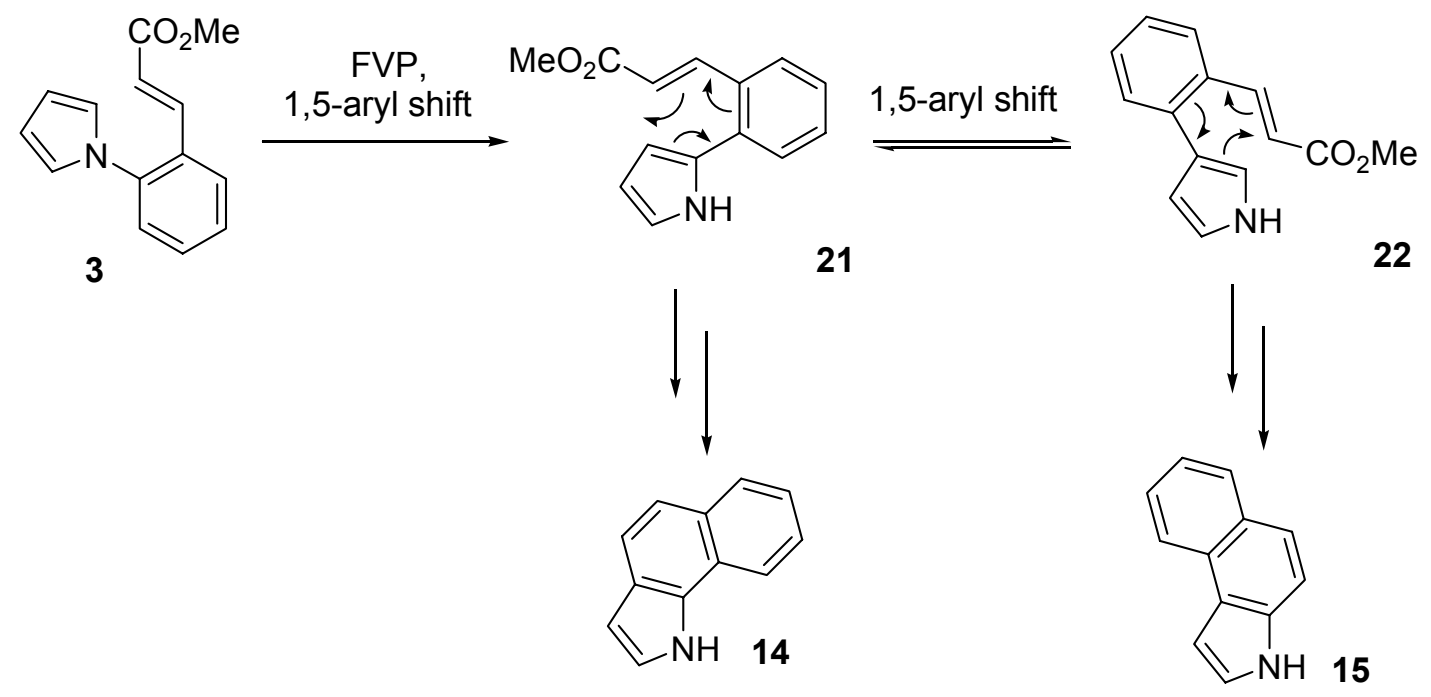

\section{Scheme 7}

The formation of the pyrroloisoindole $\mathbf{1 3}$ is unusual (formal loss of $\mathrm{C}_{2} \mathrm{H}_{2} \mathrm{O}_{2}$ from the starting material) but a possible mechanism is shown in Scheme 8. We propose that the initial 1,5-aryl shift is followed by a 1,9- $\mathrm{H}$ shift leading to the intermediate $\mathbf{2 3}$ which can collapse to 2(pyrrol-2-yl)styrene 24 by loss of $\mathrm{CH}_{2}=\mathrm{O}$ and $\mathrm{CO}$. A further 1,9-H shift leads to the $o$-quinone dimethide 25, the precursor of the final product. It is again noteworthy that a route such as this can apparently compete successfully with the expected ketene formation by methanol elimination from 21 (c.f. previous paragraph).
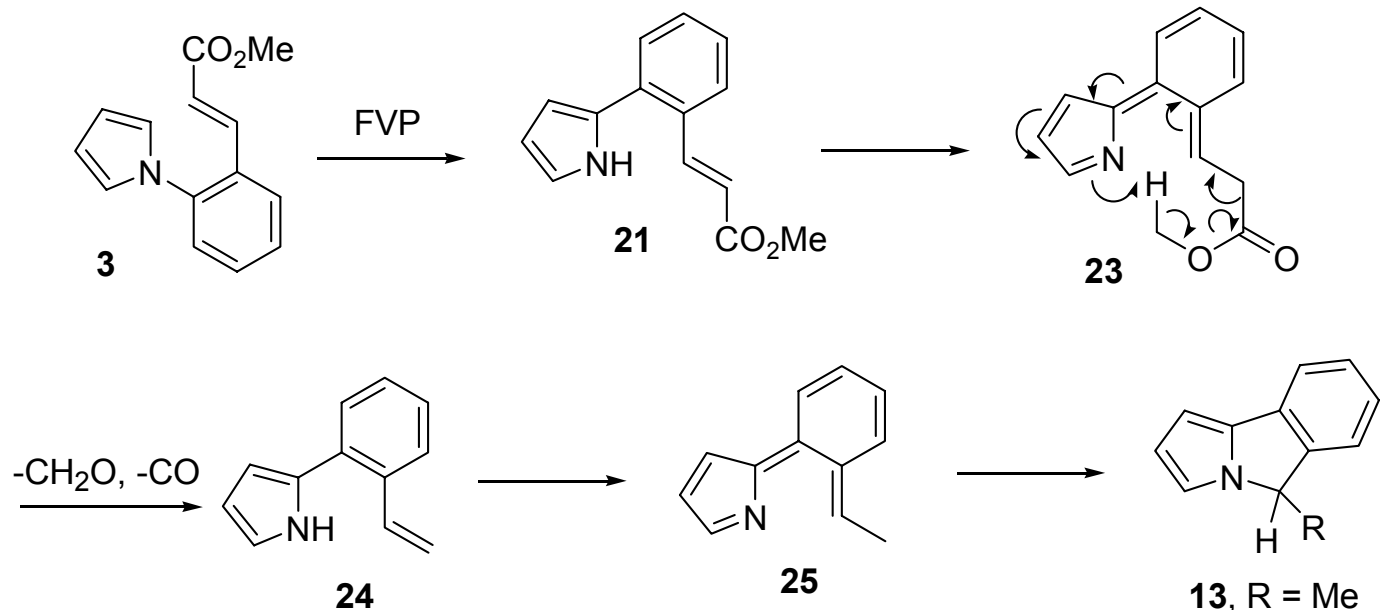

\section{Scheme 8}

In conclusion, it is clear from the results of the pyrolyses of 3 that the sequence of 1,5-aryl shift, $E / Z$ isomerisation, thermal elimination of methanol and electrocyclisation to provide a fused azepinone system, cannot compete with alternative thermal processes. Product $\mathbf{1 0}$ is 
formed from 3 even prior to the expected sigmatropic shift of the $N$-aryl group. Products 13-15 are obtained after sigmatropic shift, but are formed in preference to the azepinone $\mathbf{1 2}$ or its decomposition products (e.g. 11). We conclude that the methanol elimination step (required for the formation of $\mathbf{1 2}$ from 21) is not feasible geometrically, even though the formation of fivemembered rings (via a six- or seven-membered transition state) is highly efficient. This efficiency is illustrated by the formation of $\mathbf{1 6}$ exclusively, by pyrolysis of $\mathbf{4}$.

The substrate 3 is however left with no clearly defined route to products and a number of different pathways take place. One set of products, 10, 14 and 15, has provided a prototype of a new thermal cyclisation method, in which a newly recognised oxidative elimination of an ester group, taking place by a free-radical mechanism, provides a key aromatisation step. Further applications of this methodology in the synthesis of polycyclic ring systems are under investigation and will be reported in the near future. ${ }^{13}$

\section{Experimental Section}

General Procedures. ${ }^{1} \mathrm{H}$ and ${ }^{13} \mathrm{C}$ NMR spectra are recorded at 250 (or 200) and 63 (or 50) $\mathrm{MHz}$ respectively for solutions in $\left[{ }^{2} \mathrm{H}\right]$ chloroform unless otherwise stated. Coupling constants are quoted in $\mathrm{Hz} ;{ }^{13} \mathrm{C}$ NMR signals refer to $\mathrm{CH}$ resonances unless otherwise stated. ${ }^{1} \mathrm{H} /{ }^{13} \mathrm{C} \mathrm{HSQC}$ experiments were performed at $360 \mathrm{MHz}$ using a Bruker DPX360 NMR spectrometer with gradient selection using the INVIGPTP sequence as provided by Bruker. NOESY and COSY experiments were similarly carried out at $360 \mathrm{MHz}$. Mass spectra were obtained under electron impact conditions unless otherwise stated.

Methyl 2-nitrocinnamate (6). A solution of 2-nitrocinnamic acid 5 (4.84 g, $0.025 \mathrm{~mol})$ and anhydrous potassium carbonate $(3.82 \mathrm{~g})$ in dimethylformamide $\left(30 \mathrm{~cm}^{3}\right)$ was stirred magnetically. Iodomethane $(3.92 \mathrm{~g}, 0.028 \mathrm{~mol})$ was added dropwise over $10 \mathrm{~min}$, and the solution left to stir for $24 \mathrm{~h}$. The yellow solution was diluted with water $\left(50 \mathrm{~cm}^{3}\right)$ and extracted with diethyl ether $\left(3 \times 50 \mathrm{~cm}^{3}\right)$. The ether was washed with water $\left(6 \times 50 \mathrm{~cm}^{3}\right)$ and dried over $\mathrm{MgSO}_{4}$. The ether was removed under reduced pressure to give the solid product 6 (3.31 g, $64 \%$ ), mp $71-73{ }^{\circ} \mathrm{C}$ (lit., $\left.{ }^{16} 72-73{ }^{\circ} \mathrm{C}\right), \delta_{\mathrm{H}} 8.03\left(1 \mathrm{H}, \mathrm{d},{ }^{3} J 15.9\right), 7.98\left(1 \mathrm{H}, \mathrm{d},{ }^{3} J 10.0\right), 7.62-7.43$ $(3 \mathrm{H}, \mathrm{m}), 6.30\left(1 \mathrm{H}, \mathrm{d},{ }^{3} \mathrm{~J} 15.9\right)$ and $3.76(3 \mathrm{H}, \mathrm{s})$.

Methyl 2-aminocinnamate (7) ${ }^{3}$. Methyl 2-nitrocinnamate 6 (3.31 g, $\left.0.016 \mathrm{~mol}\right)$ was dissolved in methanol $\left(60 \mathrm{~cm}^{3}\right)$. Water $\left(7 \mathrm{~cm}^{3}\right)$ and ammonium chloride $(1.35 \mathrm{~g}, 0.025 \mathrm{~mol})$ were added. The solution was stirred and zinc dust $(9.00 \mathrm{~g})$ was added over $15 \mathrm{~min}$. After the initial reaction had subsided the solution was heated under reflux for $2 \mathrm{~h}$ and filtered hot through celite. The solution was diluted with water $\left(100 \mathrm{~cm}^{3}\right)$ and cooled in ice to separate the solid. The solid was filtered off and the solution extracted with dichloromethane $\left(3 \times 75 \mathrm{~cm}^{3}\right)$. The dichloromethane layer was separated from the aqueous layer and concentrated to give 7 as a yellow solid ${ }^{3}(1.43 \mathrm{~g}$, $51 \%) \delta_{\mathrm{H}} 7.77\left(1 \mathrm{H}, \mathrm{d},{ }^{3} J 15.7\right), 7.31\left(1 \mathrm{H}, \mathrm{dd},{ }^{3} J 8.1,{ }^{4} J 2.8\right), 7.08\left(1 \mathrm{H}, \mathrm{d},{ }^{3} J 8.1\right), 6.73-6.61(2 \mathrm{H}$, m), $6.26\left(1 \mathrm{H}, \mathrm{d},{ }^{3} J 15.8\right), 3.91\left[2 \mathrm{H}\right.$, br.s, $\left.\left(\mathrm{NH}_{2}\right)\right]$ and $3.72(3 \mathrm{H}, \mathrm{s})$. 
Methyl 2-(pyrrol-1-yl)cinnamate (3). Methyl 2-aminocinnamate 7 (0.92 g, $5 \mathrm{mmol}$ ) was added to 2,5-dimethoxytetrahydrofuran $(0.68 \mathrm{~g}, 5 \mathrm{mmol})$ with glacial acetic acid $\left(1 \mathrm{~cm}^{3}\right)$ and heated under reflux for $20 \mathrm{~min}$. The acetic acid was removed under reduced pressure and the crude product distilled by Kugelrohr distillation. The product was then purified by dry flash chromatography on silica (15\% ethyl acetate in hexane) to give methyl 2-(pyrrol-1-yl)cinnamate 3 (0.64 g, 54\%), mp 39-41 ${ }^{\circ} \mathrm{C}$, bp $92{ }^{\circ} \mathrm{C}\left(0.2\right.$ Torr) [(FAB) Found $\mathrm{MH}^{+} 228.1024 \mathrm{C}_{14} \mathrm{H}_{14} \mathrm{NO}_{2}$ requires $M H$ 228.1025], $\delta_{\mathrm{H}} 7.69-7.25(4 \mathrm{H}, \mathrm{m}), 7.56\left(2 \mathrm{H}, \mathrm{d},{ }^{3} J 16.0\right), 6.81(2 \mathrm{H}, \mathrm{s}), 6.35(1 \mathrm{H}, \mathrm{s})$, $6.32\left(1 \mathrm{H}, \mathrm{d},{ }^{3} J 16.0\right)$ and $3.76(3 \mathrm{H}, \mathrm{s}) ; \delta_{\mathrm{C}} 166.82$ (quat), 140.53 (quat), 140.34, 130.49, 130.03 (quat), 127.54, 127.36, 126.55, $122.64(2 \mathrm{C}), 119.90,109.78(2 \mathrm{C})$ and $51.62\left(\mathrm{CH}_{3}\right) ; \mathrm{m} / z$ (e.i.) 227 $\left(\mathrm{M}^{+}, 0.6 \%\right), 169$ (42), 168 (100), 167 (85), 166 (55), 140 (23), 139 (29), 128 (20), 115 (22), 83 (25), 75 (25), 63 (24) and 51 (29); $m / z$ (FAB) $228\left(\mathrm{MH}^{+}, 63 \%\right)$.

1-Phenylpyrrole-2-carbaldehyde (9). A solution of 1-phenylpyrrole 8 (9.99 g, $69.9 \mathrm{mmol})$ in DMF $\left(100 \mathrm{~cm}^{3}\right)$ was added to a solution of phosphoryl chloride $(12.9 \mathrm{~g}, 84.0 \mathrm{mmol})$ in DMF $\left(210 \mathrm{~cm}^{3}\right)$ and stirred for $1 \mathrm{~h}$. A further portion of phosphoryl chloride $(12.9 \mathrm{~g}, 84.0 \mathrm{mmol})$ in DMF $\left(210 \mathrm{~cm}^{3}\right)$ was added and the solution was stirred overnight. The reaction mixture was poured over crushed ice and hydrolysed using $10 \mathrm{M}$ sodium hydroxide $\left(100 \mathrm{~cm}^{3}\right)$ and neutralised with hydrochloric acid. The mixture was then extracted with ether $\left(4 \times 300 \mathrm{~cm}^{3}\right)$ and washed with water $\left(250 \mathrm{~cm}^{3}\right)$, dried $\left(\mathrm{MgSO}_{4}\right)$ and concentrated under reduced pressure to give a brown oil. Distillation (Kugelrohr) of the crude product yielded the 1-phenylpyrrolecarbaldehyde as a mixture of the 2- and 3-isomers (11.07 g, 93\%). A portion of the 1-phenylpyrrolecarbaldehyde mixture $(2.68 \mathrm{~g}, 15.7 \mathrm{mmol})$ was separated into the two isomers using dry flash chromatography to yield 1-phenylpyrrole-2-carbaldehyde ${ }^{17} 9(2.44 \mathrm{~g}, 91 \%) \delta_{\mathrm{H}} 9.65(1 \mathrm{H}, \mathrm{s}), 7.40-7.59(5 \mathrm{H}, \mathrm{m})$, $7.24(1 \mathrm{H}, \mathrm{dd}, J 4.3$ and 1.8), $7.15(1 \mathrm{H}, \mathrm{t}, J 1.8)$ and $6.48(1 \mathrm{H}, \mathrm{dd}, J 3.9$ and 2.3$)$.

Methyl 3-(1-phenylpyrrol-2-yl)propenoate (4). 1-Phenylpyrrole-2-carbaldehyde 9 (2.44 g, $14.3 \mathrm{mmol}$ ) was added to a solution of methyl (triphenylphosphoranylidene)acetate $(4.80 \mathrm{~g}, 14.4$ mmol) in toluene $\left(50 \mathrm{~cm}^{3}\right)$ and stirred under reflux for $6 \mathrm{~h}$. The reaction product was concentrated under reduced pressure, absorbed onto silica and then separated using dry flash chromatography (10\% ethyl acetate in $n$-hexane). The resulting solution was then distilled (Kugelrohr) to leave the product as orange crystals. The final product was recrystallised from hexane to give the methyl 3-(1-phenylpyrrol-2-yl)propenoate $4(0.91 \mathrm{~g}, 28 \%) \mathrm{mp} 61{ }^{\circ} \mathrm{C}$ [Found, $\mathrm{M}^{+} 227.0951 . \mathrm{C}_{14} \mathrm{H}_{13} \mathrm{NO}_{2}$ requires $\left.M 227.0946\right] \delta_{\mathrm{H}} 7.3-7.5(6 \mathrm{H}, \mathrm{m}) 6.97(1 \mathrm{H}, \mathrm{m}), 6.82(1 \mathrm{H}, \mathrm{m})$, $6.35(1 \mathrm{H}, \mathrm{m}) 6.09\left(1 \mathrm{H}, \mathrm{d},{ }^{3} J 15.4\right)$ and $3.71(3 \mathrm{H}, \mathrm{s}) ; \delta_{\mathrm{C}} 167.98$ (quat), 138.84 (quat), 133.37, $129.43(2 \mathrm{CH}), 127.99,126.72,126.32(2 \mathrm{CH}), 113.18,112.34,110.44$ and $51.40\left(\mathrm{CH}_{3}\right)$ (one quaternary signal not apparent); $m / z 227\left(\mathrm{M}^{+}, 32 \%\right), 196$ (27), 168 (84), 167 (100) and 51 (20).

\section{Flash vacuum pyrolysis (FVP) experiments}

The precursor was volatilised under rotary pump vacuum (pumping speed $100 \mathrm{dm}^{3} \mathrm{~min}^{-1}$ ) through an empty, electrically heated silica tube $(35 \times 2.5 \mathrm{~cm})$ and the products were collected in a liquid nitrogen trap situated at the exit point of the furnace. The pressure was measured by a Pirani gauge situated between the product trap and the pump. The precursor, pyrolysis 
conditions [quantity of precursor, furnace temperature $\left(T_{\mathrm{f}}\right)$, inlet temperature $\left(T_{\mathrm{i}}\right)$, pressure range $(P)$ and pyrolysis time $(t)]$ and products are given.

FVP of methyl 2-(pyrrol-1-yl)cinnamate (3). Methyl 2-(pyrrol-1-yl)cinnamate 3 (50 mg, 0.22 mmol) was distilled at $40-75{ }^{\circ} \mathrm{C}(0.05$ Torr $)$ into the furnace tube which was maintained at temperatures of 800,850 or $900{ }^{\circ} \mathrm{C}$. The optimum furnace temperature for complete conversion of starting material was $850{ }^{\circ} \mathrm{C}$. A preparative pyrolysis of $3(0.363 \mathrm{~g}, 1.6 \mathrm{mmol})$ was performed under the following conditions: $T_{\mathrm{f}} 850{ }^{\circ} \mathrm{C}, T_{\mathrm{i}} 50-100{ }^{\circ} \mathrm{C}, P$ 0.07-0.01 Torr, $t 100$ min. Reaction products were separated by dry flash chromatography on silica using a hexane/ethyl acetate gradient as eluent (isolated products $0.146 \mathrm{~g}, 40 \%$ ). The following components were identified, in order of elution: pyrrolo[1,2-a]quinoline $10(21 \mathrm{mg}, 8 \%) \delta_{\mathrm{H}} 7.88\left(1 \mathrm{H}, \mathrm{d},{ }^{3} J 8.8\right), 7.85(1 \mathrm{H}, \mathrm{dd}$, $\left.{ }^{3} J 2.9,{ }^{4} J 1.4\right), 7.64\left(1 \mathrm{H}, \mathrm{dd},{ }^{3} J 7.8,{ }^{4} J 1.5\right), 7.49\left(1 \mathrm{H}, \mathrm{ddd},{ }^{3} J 7.2\right.$ and $\left.8.6,{ }^{4} J 1.5\right), 7.34-7.26(2 \mathrm{H}$, m), $6.98\left(1 \mathrm{H}, \mathrm{d},{ }^{3} J 8.8\right), 6.78\left(1 \mathrm{H}, \mathrm{dd},{ }^{3} J 3.8\right.$ and 2.9$)$ and $6.52\left(1 \mathrm{H}, \mathrm{dd},{ }^{3} J 3.8,{ }^{4} J 1.4\right) ; \delta_{\mathrm{C}} 133.3$ (quat), 130.9 (quat), 128.4, 127.5, 123.7 (quat), 123.3, 118.8, 118.5, 114.0, 112.5, 111.8 and 102.6; m/z $167\left(\mathrm{M}^{+}, 100 \%\right), 166$ (20), 139 (13), 123 (17), 105 (28), 69 (32), 57 (34), 43 (48) and 41 (45), spectra consistent with those in the literature: ${ }^{5,6} 5$-methyl-5H-pyrrolo[2,1-a]isoindole 13 $(\mathrm{R}=\mathrm{Me})(30 \mathrm{mg},<11 \%)$, as the major component of an impure fraction (Found, $\mathrm{M}^{+} 169.0893$. $\mathrm{C}_{12} \mathrm{H}_{11} \mathrm{~N}$ requires $\left.M 169.0892\right) \delta_{\mathrm{H}}(360 \mathrm{MHz}) 7.52\left(1 \mathrm{H}, \mathrm{d},{ }^{3} J 7.4\right), 7.34(2 \mathrm{H}, \mathrm{m}), 7.21\left(1 \mathrm{H}, \mathrm{t},{ }^{3} J\right.$ ca. 7.4), $6.97(1 \mathrm{H}, \mathrm{m}), 6.41\left(1 \mathrm{H}, \mathrm{dd},{ }^{3} J 3.5\right.$ and 2.6$), 6.33\left(1 \mathrm{H}, \mathrm{dd},{ }^{3} J 3.5,{ }^{4} J 1.1\right), 5.08\left(1 \mathrm{H}, \mathrm{q},{ }^{3} J\right.$ $6.9)$ and $1.68\left(3 \mathrm{H}, \mathrm{d},{ }^{3} J 6.9\right) ; \delta_{\mathrm{C}}$ (quaternary signals not quoted) $127.85,124.73,122.16,118.38$, 114.65, 112.51, 97.90, 56.90 and $20.89\left(\mathrm{CH}_{3}\right) ; \mathrm{m} / \mathrm{z} 169\left(\mathrm{M}^{+}, 88 \%\right)$ and $154(100): 1 H_{-}$ benz $[g]$ indole 14 as the minor component in a mixture with $15,\left(37 \mathrm{mg}, 14 \%\right.$ total) $\delta_{\mathrm{H}} 8.85(1 \mathrm{H}$, br, NH), 7.96-7.91 (2H, m), $7.74\left(1 \mathrm{H}, \mathrm{dd},{ }^{3} J 8.8,{ }^{4} J 0.7\right), 7.63-7.40(3 \mathrm{H}, \mathrm{m}), 7.24(1 \mathrm{H}, \mathrm{m})$ and $6.70\left(1 \mathrm{H}, \mathrm{dd},{ }^{3} \mathrm{~J} 3.0,{ }^{4} \mathrm{~J} 2.1\right) ; \delta_{\mathrm{C}}\left(\mathrm{CH}\right.$ signals only, literature data ${ }^{10}$ in parentheses) $128.7(128.9)$, 125.3 (125.4), 123.7 (123.9), 122.6 (122.2), 120.7 (120.8), 120.6 (120.8), 119.2 (119.3) and 104.2 (104.3): a pure fraction of $3 H$-benz[e]indole 15 was also obtained, $\delta_{\mathrm{H}}(360 \mathrm{MHz}) 8.42$ (1H, br, NH), $8.27\left(1 \mathrm{H}, \mathrm{dm},{ }^{3} J 8.1,{ }^{4} J 1.4,{ }^{5} J\right.$ and $\left.{ }^{\mathrm{n}} J 0.7\right), 7.94\left(1 \mathrm{H}, \mathrm{dm},{ }^{3} J 8.1,{ }^{4} J 1.4,{ }^{5} J\right.$ and ${ }^{\mathrm{n}} J$ 0.7), $7.64\left(1 \mathrm{H}, \mathrm{d},{ }^{3} J 8.9\right), 7.59$ (1H, ddd, ${ }^{3} J 8.1$ and $\left.6.9,{ }^{4} J 1.4\right), 7.57\left(1 \mathrm{H}, \mathrm{dd},{ }^{3} J 8.9,{ }^{4} J 0.9\right), 7.46$ (1H, ddd, ${ }^{3} J 8.1$ and $\left.6.9,{ }^{4} J 1.4\right) 7.32\left(1 \mathrm{H}\right.$, ddd, ${ }^{3} J 2.9,{ }^{4} J 2.5$ and $\left.{ }^{\mathrm{n}} J 0.3\right)$ and $7.14\left(1 \mathrm{H}\right.$, ddd, ${ }^{3} J$ $2.9,{ }^{4} J 2.1$ and ${ }^{\mathrm{n}} J 0.9$ ); $\delta_{\mathrm{C}}(90 \mathrm{MHz}) 132.60$ (quat), 129.58 (quat), 128.93, 128.62 (quat), 126.19, $123.75,123.41$ (2C), 123.23 (quat), 122.59, 113.16 and 102.37; $\mathrm{m} / z 167\left(\mathrm{M}^{+}, 100 \%\right), 155$ (12), 140 (23), 139 (32), 105 (14), 86 (35), 84 (68) and 77 (14).

FVP of methyl 3-(1-phenylpyrrol-2-yl) propenoate (4). Methyl 3-(1-phenylpyrrol-2-yl) propenoate $4(0.514 \mathrm{~g}, 2.26 \mathrm{mmol})$ was pyrolysed as above using the following parameters: $T_{\mathrm{f}}$ $850{ }^{\circ} \mathrm{C}, T_{\mathrm{i}} 55-60{ }^{\circ} \mathrm{C}, P 0.01$ Torr. The pyrolysate was absorbed onto silica and separated using dry flash chromatography ( $1 \%$ ethyl acetate in $n$-hexane) to give 5-phenylpyrrolizin-3-one 16 (0.169 g, 38\%) bp $98{ }^{\circ} \mathrm{C}$ (0.4 Torr) [lit., ${ }^{1} 97-98{ }^{\circ} \mathrm{C}(0.2$ Torr $)$; $\delta_{\mathrm{H}} 7.81-7.85$ (2H, m), 7.25-7.49 $(3 \mathrm{H}, \mathrm{m}), 7.10(1 \mathrm{H}, \mathrm{d}, J 5.8), 6.18(1 \mathrm{H}, \mathrm{dd}, J 3.6$ and 0.7$), 6.07(1 \mathrm{H}, \mathrm{d}, J 3.3)$ and $5.70(1 \mathrm{H}, \mathrm{dd}, J$ 5.8 and 0.4 ); $\delta_{\mathrm{C}} 166.21$ (quat), 138.69 (quat), 138.49 (quat), 137.53, 129.63 (quat), 128.62, $128.14(2 \mathrm{CH}), 126.75(2 \mathrm{CH}), 121.76,114.64$ and 112.17; $m / z 195\left(\mathrm{M}^{+}, 100 \%\right), 167$ (33), 139 
(13) and 115 (11). Note that the chemical shift of the signal at $\delta_{\mathrm{H}} 5.70$ is wrongly reported as 5.09 in ref. 1 ; the spectra are otherwise compatible with those previously listed. ${ }^{1}$

\section{Acknowledgements}

We are grateful to the Engineering and Physical Sciences Research Council for the award of the $360 \mathrm{MHz}$ NMR spectrometer.

\section{References}

1. Campbell, S. E.; Comer, M. C.; Derbyshire, P. A.; Despinoy, X. L. M.; McNab, H.; Morrison, R.; Sommerville, C. C.; Thornley, C. J. Chem. Soc., Perkin Trans. 1 1997, 2195.

2. McNab, H.; Parsons, S.; Stevenson, E. J. Chem. Soc., Perkin Trans. 1 1999, 2047.

3. Skinner, W. A.; Schelstraete, M. G. M.; Baker, B. R. J. Org. Chem. 1961, 26, 1554.

4. Garofalo, A.; Ragno, G.; Campiani, G.; Brizzi, A.; Nacci, V. Tetrahedron 2000, 56, 9351.

5. Heffernan, M. L.; Irvine, G. M. Aust. J. Chem. 1976, 29, 847.

6. Jones, A. J.; Hanisch, P.; Heffernan, M. L.; Irvine, G. M. Aust. J. Chem. 1980, 33, 499.

7. Tominaga, Y.; Shiroshita, Y.; Kurokawa, T.; Gotou, H.; Matsuda Y.; Hosomi, A. J. Heterocycl. Chem. 1989, 26, 477.

8. Clark, B. A. J.; Despinoy, X. L. M.; McNab, H.; Sommerville, C. C.; Stevenson, E. J. Chem. Soc., Perkin Trans. 1 1999, 2049.

9. Stevenson, E. Ph.D. thesis, The University of Edinburgh, 1998.

10. Baudin, J.-B.; Julia, S. A.; Ruel, O. Tetrahedron 1987, 43, 881.

11. Sakamoto, T.; Kondo, Y.; Yamanaka, H. Heterocycles 1986, 24, 1845.

12. Hickson, C. L.; McNab, H. J. Chem. Res. (S) 1989, 176.

13. McMillan, F. M.; McNab, H.; Milligan, A. A.; Tipping, I. D.; Tyas, R. G. unpublished work.

14. Claes, L.; François, J.-P.; Deleuze, M. S. J. Am. Chem. Soc. 2003, 125, 7129.

15. Jones, D. W.; Marmon, R. J. J. Chem. Soc., Perkin Trans. 1 1993, 681.

16. Kadaba, P. K. Synthesis 1971, 316.

17. Defoin, A.; Geffroy, G.; Le Nouen, D.; Spileers, D.; Streith, J. Helv. Chim. Acta 1989, 72, 1199. 